\title{
Enterovirus type 71-immunized chicken egg yolk immunoglobulin has cross antiviral activity against coxsackievirus A16 in vitro
}

\author{
ENYI GAO ${ }^{1}$, SHUWEN WU ${ }^{2}$, QING XU ${ }^{1}$, YONGLIAN ZENG ${ }^{1}$, NING TAN ${ }^{1}$, \\ SONGQING HE$^{1}$, YANG YANG ${ }^{1}$ and JINGCHEN WEI ${ }^{1}$ \\ ${ }^{1}$ Department of Pharmacology, Guilin Medical University, Guilin, Guangxi 541000; \\ ${ }^{2}$ Department of State Key Laboratory of Virology, School of Life Sciences, \\ Wuhan University, Wuhan, Hubei 430000, P.R. China
}

Received July 29, 2018; Accepted April 16, 2019

DOI: $10.3892 /$ etm.2019.7529

\begin{abstract}
To exploit a cross passive immunotherapy for enterovirus-induced hand-foot-and-mouth disease (HFMD), the cross antiviral activity of a neutralizing antibody against enterovirus 71 (EV71) and coxsackievirus A16 (CVA16) was investigated in vitro. White Leghorn specific-pathogen-free chickens were immunized with EV71 antigens and a specific isolated immunoglobulin (IgY) was prepared from the chicken egg yolk. IgY was further purified and characterized by SDS-PAGE, ELISA, western blotting and bidirectional immune agar diffusion testing. The antiviral activity and dose-response of the IgY were determined by assessing the cytopathic effect in rhabdomyosarcoma (RD) cells in vitro. It was indicated that the levels of $\operatorname{IgY}$ were increased at day 7, peaked at week 7 and were maintained at a higher level for 4 weeks following immunization when compared with the negative control. The results of western blotting and bidirectional immune agar diffusion testing revealed that the IgY had cross-binding properties in EV71 and CVA16 strains through targeting the envelope proteins (VP0, VP1 and VP3) of EV71 and CVA16. Neutralization assay results indicated that the infectivity of EV71 and CVA16 strains in RD cells was cross-blocked by IgY in a dose-dependent manner. To conclude, these findings indicate that IgY has cross antiviral activity against EV71 and CVA16 in vitro, and could potentially be developed as a passive immunotherapy for EV71- and CVA16-induced HFMD.
\end{abstract}

\section{Introduction}

Hand-foot-and-mouth disease (HFMD) is an infantile disease characterized by herpes on the hands, feet and mouth, and

Correspondence to: Professor Jingchen Wei or Professor Yang Yang, Department of Pharmacology, Guilin Medical University, 109 Huancheng North Road, Guilin, Guangxi 541000, P.R. China E-mail: m13707735076@163.com

E-mail: 82579354@qq.com

Key words: enterovirus 71, coxsackievirus A16, IgY, rhabdomyosarcoma cells, antiviral activity associated neurological syndrome $(1,2)$. The major viruses that cause HFMD are EV71 and CVA16. EV71-induced HFMD is more serious out of the two because it causes a neurological syndrome of the central nervous system and may lead to mortality (3). CVA16-induced HFMD usually leads to milder symptoms, and the morbidity and mortality are lower compared with EV71-induced HFMD (4). However, EV71 is not the only major cause of HFMD outbreak. Zhu et al (5) conducted a 12-month follow-up of 1,704 patients with clinically confirmed HFMD and revealed that only 36 cases (2.1\%) were identified as EV71-induced HFMD, 577 cases (33.9\%) were CVA16-induced HFMD, 588 cases (34.5\%) were caused by other enteroviruses and 503 cases $(29.5 \%)$ were not associated with any enterovirus. Furthermore, some patients with severe and fatal CVA16-induced HFMD have been reported in the United States (6), France (7), Japan (8) and China $(9,10)$.

The experimental treatment for HFMD includes inactivated virus vaccine $(5,11)$, DNA vaccine $(12)$, synthetic peptide vaccine $(13,14)$, recombinant VP1 vaccine $(15)$, live attenuated vaccines (16), neutralizing antibodies (17) and antiviral compounds (18). Inspired by previous inactivated polio vaccines, the development of an active immunoassay for inactivated EV71 vaccine has been making rapid progress (19). In December 2015, the China Food and Drug Administration approved two inactivated EV71 vaccines for the prevention of severe HFMD (20), and a CVA16 vaccine is presently being developed in China (21). However, these vaccines only provide protection against HFMD caused by a single enterovirus. The clinical symptoms of HFMD caused by CVA16 and EV71 strains are indistinguishable, and they may cause outbreaks alternately or simultaneously in Asian countries (22). EV71 can recombine viral genes with CVA16 and produce novel viral variants. In 2008, a large-scale outbreak of HFMD caused by EV71 and CVA16 recombinant virus occurred in the city of Fuyang, China (23). Therefore, it is necessary to develop effective therapeutic agents or therapies for treatment of EV71- and CVA16-induced HFMD.

In passive immunization, intravenous injection of human immunoglobulins has been widely used to provide immunological protection with passive immunity for immunocompromised individuals (24); however, the therapeutic 
efficacy is unstable (25), and the risk of adverse drug effects is high (26). The monoclonal antibody produced by hybridoma cells is another form of passive immunity that is effective (27). However, when the antibody is injected into humans, immune rejection typically occurs (28). Immunoglobulin Y (IgY), which is extracted from the egg yolk of immunized poultry, is an excellent antibody source for passive immunity (29). Compared with the $\mathrm{IgG}$ from mammals, IgY is more stable $(30,31)$, easy to collect (32), has a high yield (33) and does not react with rheumatoid factors, complement components or mammalian Fc receptors in human serum (34). At present, the application of IgY in the diagnosis and treatment of human diseases has become a research hotspot, particularly regarding infections caused by Helicobacter pylori (35), Vibrio cholerae (36) and other bacterial infections, as well as the infections by human rotavirus (37), severe acute respiratory syndrome coronavirus (38) and other viruses. IgY can also be used for the preparation of diagnostic antibodies for immunohistochemistry, ELISA (39), western blotting and other diagnostic techniques.

In the present study, the cross antiviral activity of $\operatorname{IgY}$ against EV71 and CVA16 was assessed. White Leghorn specific-pathogen-free (BWEL-SPF) chickens were immunized with inactivated EV71 strains and a specific IgY was prepared from egg yolk. Inhibitory activity of the IgY against EV71 and CVA16 strains was indicated in vitro. Furthermore, the purity and titer of the IgY was determined by SDS-PAGE, indirect ELISA and western blotting. The long-term aim of the present project was to develop a specific IgY that could potentially act as an antiviral agent for cross-passive immunotherapy of EV71- or CVA16-induced HFMD.

\section{Materials and methods}

Cells and viruses. Rhabdomyosarcoma (RD) cells were obtained from the China Center for Type Culture Collection (Wuhan, China). EV71, CVA16, coxsackievirus B1 (CVB1), coxsackievirus B2 (CVB2), coxsackievirus B3 (CVB3), coxsackievirus B4 (CVB4), coxsackievirus B5 (CVB5) and coxsackievirus B6 (CVB6) were purchased from the State Key Laboratory of Virology (Wuhan, China) and diluted (1:5) in Dulbecco's modified Eagle's medium (DMEM; Gibco; Thermo Fisher Scientific, Inc., Waltham, MA, USA) supplemented with $10 \%$ fetal bovine serum (FBS; Corning Inc., Corning, NY, USA), $100 \mathrm{U} / \mathrm{ml}$ penicillin (Sigma-Aldrich; Merck KGaA, Darmstadt, Germany) and $100 \mu \mathrm{g} / \mathrm{ml}$ streptomycin (Sigma-Aldrich; Merck KGaA). $\mathrm{RD}$ cells were cultured in virus-containing medium at $37^{\circ} \mathrm{C}$ in a $5 \% \mathrm{CO}_{2}$-humidified incubator. When RD cells containing the viruses reached $\sim 80 \%$ confluence, cells were frozen-thawed at $-80^{\circ} \mathrm{C}$, centrifuged at $2,000 \mathrm{xg}$ for $5 \mathrm{~min}$ at $4^{\circ} \mathrm{C}$ and filtered on a $0.22-\mu \mathrm{M}$ filter for storage.

Chicken immunization. A total of 639 -week-old single-comb BWEL-SPF chickens were purchased from the SPF Experimental Animal Center of Guangdong Emerging Dahua Agriculture Poultry Co., Ltd. (Guangzhou, China). Chickens were raised in 3 super-clean benches (Suzhou Antai Airtech Co. Ltd., Suzhou, China) and had access to food and water (pH 6.2). After 1 week, laying chickens were divided into two groups: Group A and Group B. After mixing the EV71 antigen $\left(10^{9} \mathrm{TCID}_{50} / \mathrm{ml}\right)$ with an equal amount of Freund's incomplete adjuvant and fully emulsifying, 3 chickens were randomly selected for Group A and injected intramuscularly in both sides of the chicken wings and left and right sides of the breast $(0.25 \mathrm{ml} / \mathrm{site})$. In Group B, 3 chickens were given a mixture $(1 \mathrm{ml})$ of saline and Freund's incomplete adjuvant $(0.25 \mathrm{ml} / \mathrm{site})$. In Groups A and B, the injections were performed once/week for 4 weeks. Eggs were collected once a day, labeled and stored at $4^{\circ} \mathrm{C}$. Chickens were euthanized at week 31 , following the first immunization.

Isolation and purification of IgY from chicken egg yolk. Once the fresh eggs were cleaned with $75 \%$ alcohol and cotton balls, the egg yolks were separated and the extra albumen was rolled off with filter paper. The egg yolk without the membrane was diluted with cold deionized water (1:9), mixed (adjusted to $\mathrm{pH} 5.0$ with $0.1 \mathrm{~mol} \mathrm{HCl}$ ) and then stored at $4^{\circ} \mathrm{C}$ overnight. The solution was centrifuged at $4,000 \mathrm{x}$ f for $40 \mathrm{~min}$ at $4^{\circ} \mathrm{C}$ and the supernatant was added to ammonium sulphate to make a final saturation of $45 \%$. Following this, the solution was incubated at $4^{\circ} \mathrm{C}$ for $3 \mathrm{~h}$. After centrifugation at $4,000 \mathrm{x}$ for $10 \mathrm{~min}$ at $4^{\circ} \mathrm{C}$, the supernatant was discarded and deionized water (9 times the volume of egg yolk without the membrane) was used to dissolve the protein precipitate. Subsequently, sodium sulfate was added to make a final mass fraction of $13 \%$. The mixture was incubated at $4^{\circ} \mathrm{C}$ for $3 \mathrm{~h}$ and centrifuged again under the same conditions. The sediment was dissolved in phosphate-buffered saline (PBS). The solution was dialyzed for 4-5 h (water changed every hour), soaked in PBS overnight and stored at $-20^{\circ} \mathrm{C}$. The IgY purified from eggs of group A after immunization were the specific IgY (S-IgY), and those from group B were the negative control IgY (C-IgY). The purified IgY was subjected to centrifugal ultrafiltration at 4,000 $\mathrm{x} g$ for $10 \mathrm{~min}$ at $4^{\circ} \mathrm{C}$ using an Amicon Ultra-15 centrifugal filter unit (EMD Millipore, Billerica, MA, USA) to desalt and concentrate the antibody. The purified IgY was used in subsequent in vitro neutralization assays and western blotting.

Quantitation of the purfied IgY. The antibody titer of the S-IgY and C-IgY (purified IgY) was determined using indirect ELISA. The purified IgY from egg yolk was diluted to 1:5,000 in PBS, and $50 \mu \mathrm{l}$ was added to the ELISA plate, which had been coated with the purified EV71 antigen. Three duplicated wells were set in the same sample, the C-IgY group or the S-IgY group. The plate was covered, incubated at $37^{\circ} \mathrm{C}$ for $30 \mathrm{~min}$ and the wells were washed 5 times ( $30 \mathrm{~min}$ each time) with a washing buffer provided in an EV71 Ab ELISA kit (cat. no. SBJ-H2014; Nanjing SenBeiJia Biological Technology Co., Ltd., Nanjing, China). The plate was incubated with horseradish peroxidase (HRP)-conjugated goat anti-chicken IgY antibody (1:2,000; Abcam, Cambridge, MA, USA) for $30 \mathrm{~min}$ at $37^{\circ} \mathrm{C}$, washed 5 times with a washing buffer $(30 \mathrm{sec}$ each time) and subsequently incubated with $100 \mu \mathrm{l}$ freshly prepared TMB color liquid (50 $\mu \mathrm{l}$ each of color liquid $\mathrm{A}$ and $\mathrm{B}$ ) at $37^{\circ} \mathrm{C}$ in the dark for $15 \mathrm{~min}$. Following color development, $50 \mu \mathrm{l}$ of $2 \mathrm{~mol} \mathrm{H}_{2} \mathrm{SO}_{4}$ was added to stop the reaction and the absorbance was measured immediately at $450 \mathrm{~nm}$ using a Bio-Tek EL 309 microplate reader (Omega Bio-Tek, Inc., Norcross, GA, USA). The concentration of the IgY was obtained according to the standard curves. 
Table I. Primary and secondary antibodies.

\begin{tabular}{|c|c|c|c|c|c|c|}
\hline Protein & Primary antibody & $\begin{array}{l}\text { Dilution } \\
\text { used }\end{array}$ & Catalogue number & Secondary antibody & $\begin{array}{l}\text { Dilution } \\
\text { used }\end{array}$ & $\begin{array}{c}\text { Catalogue } \\
\text { number }\end{array}$ \\
\hline \multirow[t]{3}{*}{ EV71 } & C-IgY & $1: 20,000$ & & HRP goat anti-chicken IgY & $1: 5,000$ & $a b 20572^{b}$ \\
\hline & S-IgY & $1: 20,000$ & & HRP goat anti-chicken IgY & $1: 5,000$ & $\mathrm{ab} 20572^{\mathrm{b}}$ \\
\hline & $\begin{array}{l}\text { EV71 VP1 monoclonal } \\
\text { antibody }\end{array}$ & $1: 10,000$ & MAB $1255-M 05^{\mathrm{a}}$ & HRP goat anti-mouse IgG & $1: 5,000$ & ab97023 \\
\hline \multirow[t]{3}{*}{ CVA16 } & C-IgY & $1: 5,000$ & & HRP goat anti-chicken IgY & $1: 2,500$ & $\mathrm{ab} 20572^{\mathrm{b}}$ \\
\hline & S-IgY & $1: 5,000$ & & HRP goat anti-chicken IgY & $1: 2,500$ & $\mathrm{ab} 20572^{\mathrm{b}}$ \\
\hline & $\begin{array}{l}\text { EV71 VP1 monoclonal } \\
\text { antibody }\end{array}$ & $1: 10,000$ & MAB $1255-M 05^{a}$ & HRP goat anti-mouse IgG & $1: 5,000$ & ab97023 \\
\hline EV71 VP1 & C-IgY & $1: 20,000$ & & HRP goat anti-chicken IgY & $1: 5,000$ & $\mathrm{ab} 20572^{\mathrm{b}}$ \\
\hline vaccine & S-IgY & $1: 20,000$ & & HRP goat anti-chicken IgY & $1: 5,000$ & $\mathrm{ab} 20572^{\mathrm{b}}$ \\
\hline
\end{tabular}

${ }^{\mathrm{a} A b n o v a, ~ W a l n u t, ~ C A, ~ U S A ; ~}{ }^{\mathrm{A} A b c a m}$, Cambridge, MA, USA; HRP, horseradish peroxidase; IgY, immunoglobulin Y; EV71, enterovirus 71; CVA16, coxsackievirus A16.

SDS-PAGE analysis. Samples of IgY and 5X loading buffer (4:1) were heated in a metal water bath at $95^{\circ} \mathrm{C}$ for $10 \mathrm{~min}$ and placed on ice for an additional $10 \mathrm{~min}$. Samples (10 $\mu \mathrm{l} / \mathrm{lane})$ was separated via SDS-PAGE on a $10 \%$ gel at a constant current of $45 \mathrm{~mA}$ for $50 \mathrm{~min}$. Following protein separation, the gel was stained with Coomassie Brilliant Blue R250 for 30 min and then de-stained with a de-staining solution (30 min each time). Coomassie-stained gels were imaged and protein bands were analyzed using BandScan 5.0 software (ProZyme., Hayward, CA, USA).

Western blotting. Total protein from the purified EV71 and CVA16 virus strains and the EV71 VP1 vaccine (cat. no. DAG1665; Creative Diagnostics Co., New York, NY, USA) was quantified using a bicinchoninic acid assay (Thermo Fisher Scientific, Inc.), 5X loading buffer (cat. no. P0015L; Beyotime Institute of Biotechnology, Haimen, China) was added to samples (4:1) and denatured by heating in a metal water bath at $95^{\circ} \mathrm{C}$ for $10 \mathrm{~min}$. Samples were placed on ice for $10 \mathrm{~min}$. Samples (20 $\mu \mathrm{g}$ protein/lane) were separated via SDS-PAGE on 10 and 5\% gels. The separated proteins were transferred onto polyvinylidene fluoride membranes and blocked with 5\% skimmed milk at room temperature for $90 \mathrm{~min}$. The membranes were washed five times with Tris-buffered saline containing $0.05 \%$ Tween-20 (TBST). The membranes were incubated with primary antibodies overnight on a shaking incubator at $4^{\circ} \mathrm{C}$. The membranes were washed five times with TBST. Following primary incubation, membranes were incubated with secondary antibodies for $90 \mathrm{~min}$ on a shaking incubator at room temperature and washed four times with TBST. The primary and secondary antibodies used are summarized in Table I. Protein bands were visualized using an Enhanced Chemiluminescence Western Blotting kit (Thermo Fisher Scientific, Inc.).

Bidirectional immune agar diffusion test. A $10 \mathrm{~g} / \mathrm{l}$ agarose plate was prepared, and plum-shaped holes (aperture, 3-5 mm; hole distance, 3-4 $\mathrm{mm}$ ) were punched out on the agarose plate. The inactivated EV71 virus was added to the central well and different dilutions (1:2, 1:4, 1:8, 1:16 and 1:32) of the purified IgY were added into the peripheral 6 wells. At the same time, a blank group (PBS only) was also assessed. Following this, the plate was placed upside down in a $60^{\circ} \mathrm{C}$-wet box and incubated for $24-48 \mathrm{~h}$. The formation of the precipitation line was observed.

$50 \%$ tissue culture infective dose $\left(T C I D_{50}\right)$ assay. Virus strains were serially diluted $\left(10^{-1}-10^{-10}\right)$ with DMEM supplemented with $10 \%$ FBS and titrated $100 \mu \mathrm{l} /$ well on RD monolayer cells that had been seeded in a 96-well plate at a density of $1 \times 10^{4}$ cells/well. The virus-infected cells were incubated for $48 \mathrm{~h}$ at $37^{\circ} \mathrm{C}$ in a $5 \% \mathrm{CO}_{2}$-humidified incubator before the presence of cytopathic effect (CPE) was observed under a microscope (IX73; Olympus Corporation, Tokyo, Japan). The $\mathrm{TCID}_{50}$ of the virus strains were determined according to the Reed-Muench formula (40).

In vitro neutralization assay. $\mathrm{RD}$ cells were seeded into a 48 -well plate at a concentration of $6 \times 10^{4} /$ well and cultured overnight at $37^{\circ} \mathrm{C}$. S-IgY and C-IgY were diluted to $1 \mathrm{mg} / \mathrm{ml}$ with PBS. Enviroxime (Purity, 98\%; Toronto Research Chemicals Inc., North York, ON, Canada) was dissolved in dimethyl sulfoxide at $10 \mathrm{mg} / \mathrm{ml}$ and diluted 1:10 into culture media. The experiment was divided into 4 groups: The blank control group (PBS only), the negative control IgY (C-IgY), the S-IgY groups and the Envrioxime group. Subsequently, S-IgY and C-IgY were incubated at $56^{\circ} \mathrm{C}$ for $30 \mathrm{~min}$. S-IgY, C-IgY and Enviroxime were serially diluted (1:25, 1:50, 1:100, 1:200, 1:400, 1:800, 1:1,600 and 1:3,200) with culture media, and mixed with an equal volume of EV71 $\left(200 \mathrm{TCID}_{50}\right)$ or CVA16 $\left(200 \mathrm{TCID}_{50}\right)$. The mixtures were shaken for $5 \mathrm{~min}$ and incubated at $37^{\circ} \mathrm{C}$ in a $5 \% \mathrm{CO}_{2}$-humidified incubator for $30 \mathrm{~min}$. Subsequently, RD cells were inoculated with $300 \mu \mathrm{l}$ of the mixture and incubated $\mathrm{O}_{2}$ at $37^{\circ} \mathrm{C}$ in a $5 \% \mathrm{CO}_{2}$-humidified incubator for $48 \mathrm{~h}$ to promote the antibody binding to the viruses. Neutralization titers were determined as the highest dilutions of antibody that protected at least half of RD cells in one well from CPE. 
Table II. Concentration of IgY from different chickens.

\begin{tabular}{|c|c|c|}
\hline Chicken & $\begin{array}{l}\text { Week after } \\
\text { immunization }\end{array}$ & $\begin{array}{l}\text { Concentration of } \\
\mathrm{IgY}(\mathrm{mg} / \mathrm{ml})\end{array}$ \\
\hline \multirow[t]{4}{*}{ A1 } & $0 \mathrm{~W}$ & $3.56 \pm 0.184$ \\
\hline & $4 \mathrm{~W}$ & $4.73 \pm 0.159$ \\
\hline & $8 \mathrm{~W}$ & $7.44 \pm 0.396$ \\
\hline & $12 \mathrm{~W}$ & $6.85 \pm 0.283$ \\
\hline \multirow[t]{4}{*}{$\mathrm{A} 2$} & $0 \mathrm{~W}$ & $1.97 \pm 0.934$ \\
\hline & $4 \mathrm{~W}$ & $3.31 \pm 0.131$ \\
\hline & $8 \mathrm{~W}$ & $4.57 \pm 0.098$ \\
\hline & $12 \mathrm{~W}$ & $5.07 \pm 0.042$ \\
\hline \multirow[t]{4}{*}{ A3 } & $0 \mathrm{~W}$ & $2.261 \pm 0.013$ \\
\hline & $4 \mathrm{~W}$ & $2.91 \pm 0.109$ \\
\hline & $8 \mathrm{~W}$ & $7.11 \pm 0.117$ \\
\hline & $12 \mathrm{~W}$ & $6.46 \pm 0.294$ \\
\hline \multirow[t]{4}{*}{ B1 } & $0 \mathrm{~W}$ & $2.24 \pm 0.018$ \\
\hline & $4 \mathrm{~W}$ & $4.66 \pm 0.181$ \\
\hline & $8 \mathrm{~W}$ & $5.73 \pm 0.011$ \\
\hline & $12 \mathrm{~W}$ & $7.71 \pm 0.006$ \\
\hline \multirow[t]{4}{*}{ B2 } & $0 \mathrm{~W}$ & $5.95 \pm 0.044$ \\
\hline & $4 \mathrm{~W}$ & $5.26 \pm 0.024$ \\
\hline & $8 \mathrm{~W}$ & $8.75 \pm 0.008$ \\
\hline & $12 \mathrm{~W}$ & $11.16 \pm 0.109$ \\
\hline \multirow[t]{4}{*}{ B3 } & $0 \mathrm{~W}$ & $4.39 \pm 0.156$ \\
\hline & $4 \mathrm{~W}$ & $6.55 \pm 0.113$ \\
\hline & $8 \mathrm{~W}$ & $6.50 \pm 0.085$ \\
\hline & $12 \mathrm{~W}$ & $6.27 \pm 0.052$ \\
\hline
\end{tabular}

W, week. A1-3, Group A chicken 1-3; B1-3, Group B chicken 1-3.

To detect the antiviral activity of the IgY against different enteroviruses, the S-IgY, C-IgY and EV71 VP1 monoclonal antibodies (Table II) were incubated at $56^{\circ} \mathrm{C}$ for $30 \mathrm{~min}$. Antibodies were diluted (1:25) and mixed with an equal volume of 200 TCID $_{50}$ of EV71, CVA16, CVB1, CVB2, CVB3, CVB4, CVB5 and CVB6 strains, respectively. Oscillation and incubation were performed as mentioned above. The inhibition rate was based on the $\mathrm{CPE}$.

To determine the stability of the purified IgY under different physical conditions, the $\mathrm{IgY}$ was diluted to $1 \mathrm{mg} / \mathrm{ml}$ with PBS. The diluted IgY was incubated at different temperatures $\left(4^{\circ} \mathrm{C}\right.$, room temperature, $37^{\circ} \mathrm{C}$ or $\left.60^{\circ} \mathrm{C}\right)$ for $48 \mathrm{~h}$ or was frozen-thawed (frozen at $-20^{\circ} \mathrm{C}$ and thawed at $4^{\circ} \mathrm{C}$ ) five times. Serially diluted $\operatorname{IgY}(1: 300,1: 600$ and 1:1,200) was mixed with an equal volume of EV71 strains (200 TCID ${ }_{50}$ ). The experiment was divided into 5 groups, the $4^{\circ} \mathrm{C}$ group, the room temperature (RT) group, the $37^{\circ} \mathrm{C}$ group, the $60^{\circ} \mathrm{C}$ group and the freeze-thaw group. Following this, oscillation, incubation and calculation of inhibition rate were performed as described above.

To determine the time-dependent effect of the purified IgY on EV71 infection in RD cells, the S-IgY and C-IgY were diluted to $6 \mathrm{mg} / \mathrm{ml}$ with $\mathrm{PBS}$ and were incubated at $56^{\circ} \mathrm{C}$ for 30 min. The culture supernatants of the RD cells in 48 -well

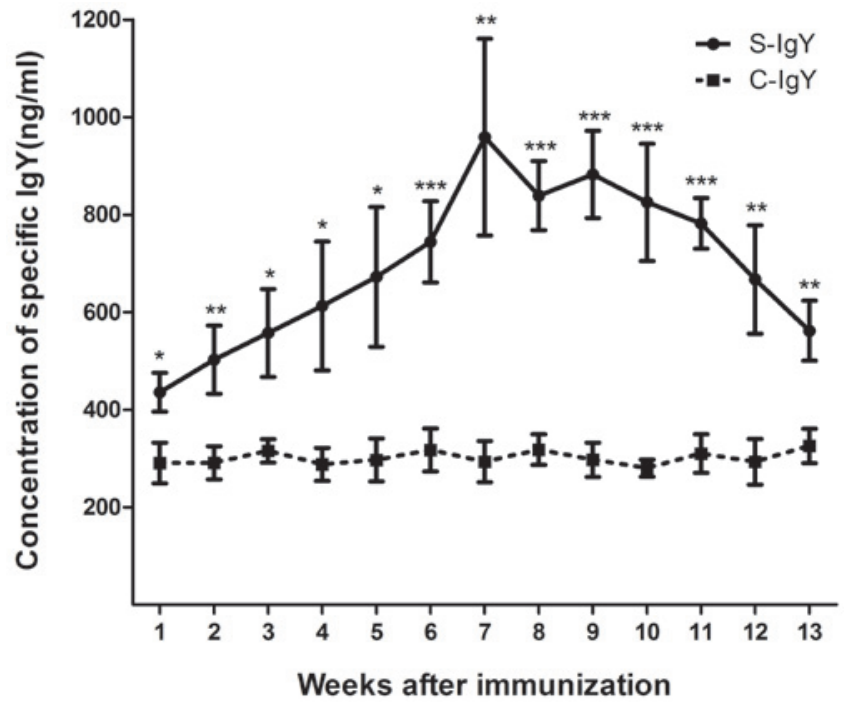

Figure 1. Levels of S-IgY in EV71-immunized chicken egg yolks. Isolation and purification of IgY from chicken egg yolk. Six 39-week-old single comb white leghorn specific-pathogen-free chickens were immunized; 3 chickens were immunized with enterovirus 71 antigens and Freund's incomplete adjuvant (group A) and the other 3 chickens were injected with saline and Freund's incomplete adjuvant (group B). Eggs were collected from immunized hens over a course of 91 days following the first immunization, and IgY was isolated and purified from the egg yolks. ${ }^{*} \mathrm{P}<0.05,{ }^{* *} \mathrm{P}<0.01$ and ${ }^{* * * *} \mathrm{P}<0.001$ vs. C-IgY. IgY, immunoglobulin Y; S-IgY, specific IgY; C-IgY, negative control IgY.

plates were replaced by $300 \mu \mathrm{l}$ EV71 strains (100 TCID $\left._{50}\right)$. A total of $1 \mu \mathrm{l} \mathrm{IgY}$ was added to the RD cells at $0,1,2,3,4$ or $5 \mathrm{~h}$ post-infection. RD cells were incubated under $5 \% \mathrm{CO}_{2}$ at $37^{\circ} \mathrm{C}$. After $48 \mathrm{~h}$ of cell culture, the inhibition rate for RD cells was obtained according to $\mathrm{CPE}$.

Statistical data analysis. All data were presented as the mean \pm standard deviation. Statistical analysis was performed using Graphpad Prism software (version 7.0; GraphPad software, La Jolla, CA, USA) and SPSS 21.0 software (IBM Corp., Armonk, NY, USA). The Student's t-test was used to evaluate differences between two groups, and one-way analysis of variance followed by Dunnett's post hoc test was used to evaluate differences among different groups. $\mathrm{P}<0.05$ was considered to indicate a statistically significant difference.

\section{Results}

Levels of IgY significantly increase in EV71-immunized chicken egg yolks. The present study was performed to isolate and purify S-IgY from EV71-immunized chicken egg yolks. As indicated in Fig. 1, the levels of S-IgY were detected at day 7 , peaked at week 7 and were maintained at a higher level compared with C-IgY for a total of 4 weeks. The levels of S-IgY began to decrease gradually at week 11 following the initial immunization, whereas the levels of the C-IgY group did not change significantly over the experimental period, suggesting that the isolated IgY is specific in its response to EV71 immunization. Furthermore, the levels of IgY in group A and group B chicken egg yolks were elevated after immunization (Table II). From these findings it was concluded that the S-IgY from week 7 chicken egg yolks after EV71 antigen 

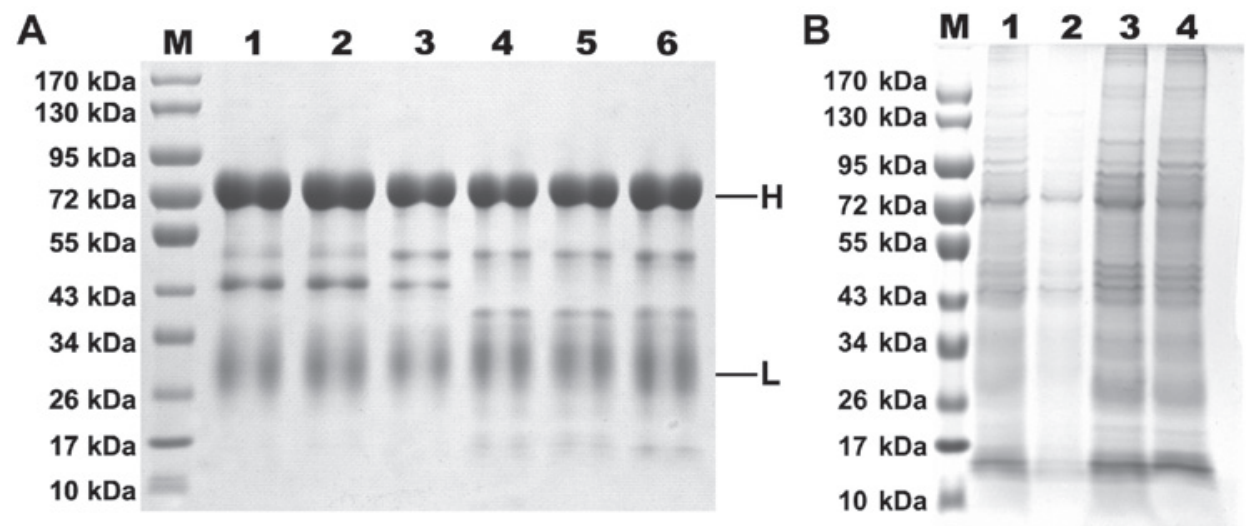

Figure 2. Characterization of the isolated IgY. (A) SDS-PAGE of the IgY antibody. Lane M: Protein markers; lanes 1, 2, and 3: IgY from the group A chickens; lanes 4, 5 and 6: IgY from the group B chickens; H and L represent the heavy chain and light chain of the IgY, respectively. (B) Viral proteins of the EV71 and CVA16 strains analyzed by SDS-PAGE. Lane 1: Protein markers; lanes 2 and 3: The CVA16 strain; lane 4 and 5: The EV71 strain. IgY, immunoglobulin Y; EV71, enterovirus 71; CVA16, coxsackievirus A16.

A

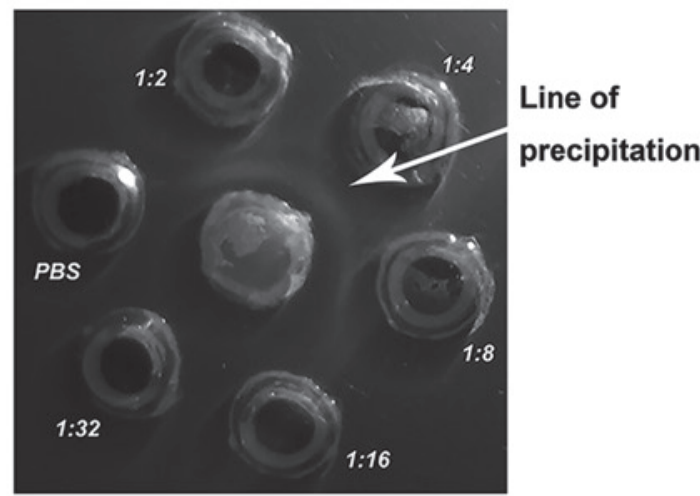

B

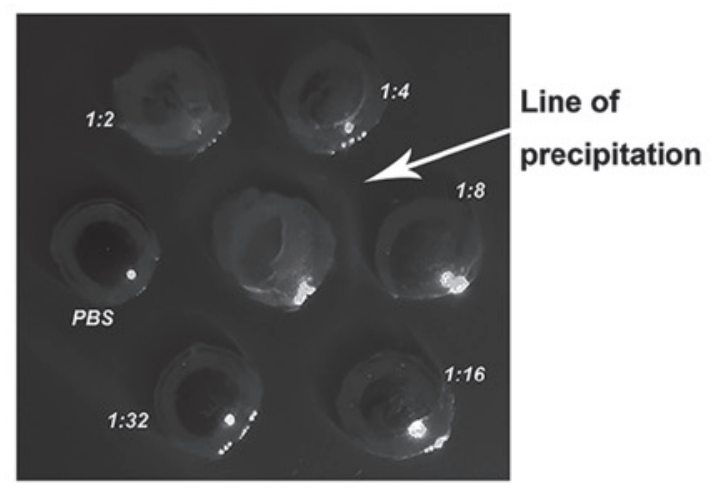

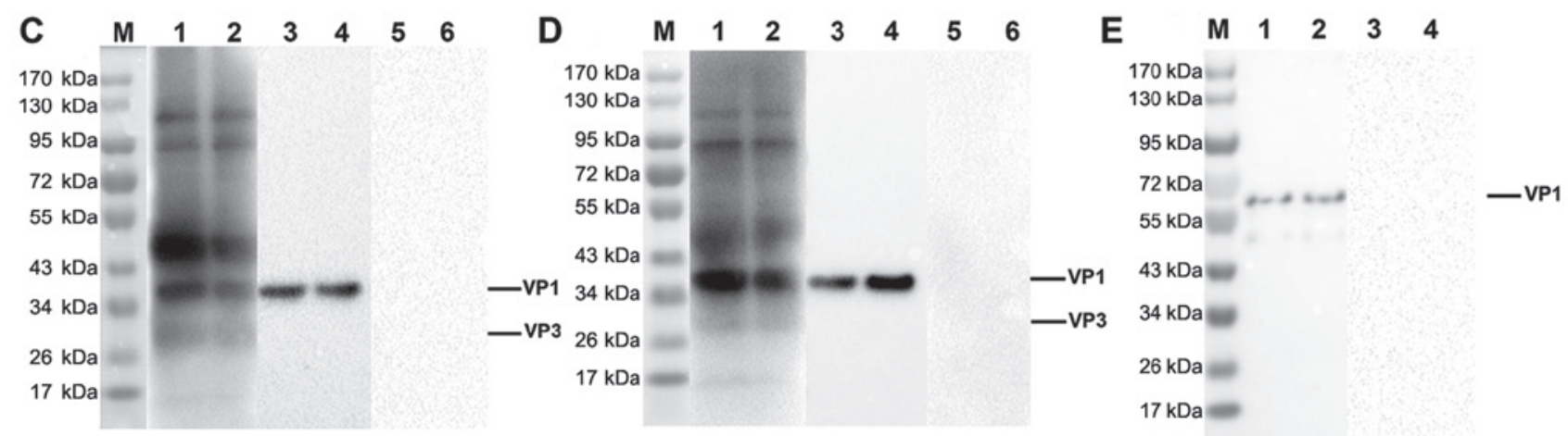

Figure 3. Characterization of the specific IgY against EV71 and CVA16 strains. (A) Bidirectional immune agar diffusion test for EV71. (B) Bidirectional immune agar diffusion test for CVA16. (C and D) Western blotting of the immunoreactivity of the specific IgY. (C) EV71 and (D) CVA16 were assessed. The EV71 and CVA16 viral extracts were subjected to SDS-PAGE, transferred to polyvinylidene fluoride membranes and detected with the specific IgY, VP1 monoclonal antibody, or the negative control IgY. Lanes 1 and 2, the isolated IgY; lanes 3 and 4, VP1 monoclonal antibody; lanes 5 and 6, negative control IgY. (E) The VP1 recombinant protein was subjected to SDS-PAGE, transferred to a polyvinylidene fluoride membrane and detected with the specific IgY or negative control IgY. Lane M, protein markers; Lanes 1 and 2, the specific IgY; lanes 3 and 4, the negative control IgY. IgY, immunoglobulin Y; EV71, enterovirus 71; CVA16, coxsackievirus A16.

immunization would be purified and used for the following experiments.

Characterization of the isolated $\operatorname{Ig} Y$. The titers of the viruses were determined using the $\mathrm{TCID}_{50}$ assay. Results indicated that the $\mathrm{TCID}_{50}$ for the EV71 strain was $10^{7.1} \mathrm{TCID}_{50} / \mathrm{ml}$, whereas the $\mathrm{TCID}_{50}$ for CVA16 strain was $10^{6.3} \mathrm{TCID}_{50} / \mathrm{ml}$. As indicated in Fig. 2, the results of SDS-PAGE demonstrated that the disulfide bond of the target protein was opened under reduction conditions, and the presence of the two dominant bands, a 70-kDa-sized species that represents the $\mathrm{H}$ chain and a $30-\mathrm{kDa}$-sized species corresponding to the $\mathrm{L}$ chain, was noted.

As the water-soluble fraction (WSF) contains a large amount of heteroprotein after egg yolk acid-isolation, water was used to dissolve the egg yolk, which was then salted out 

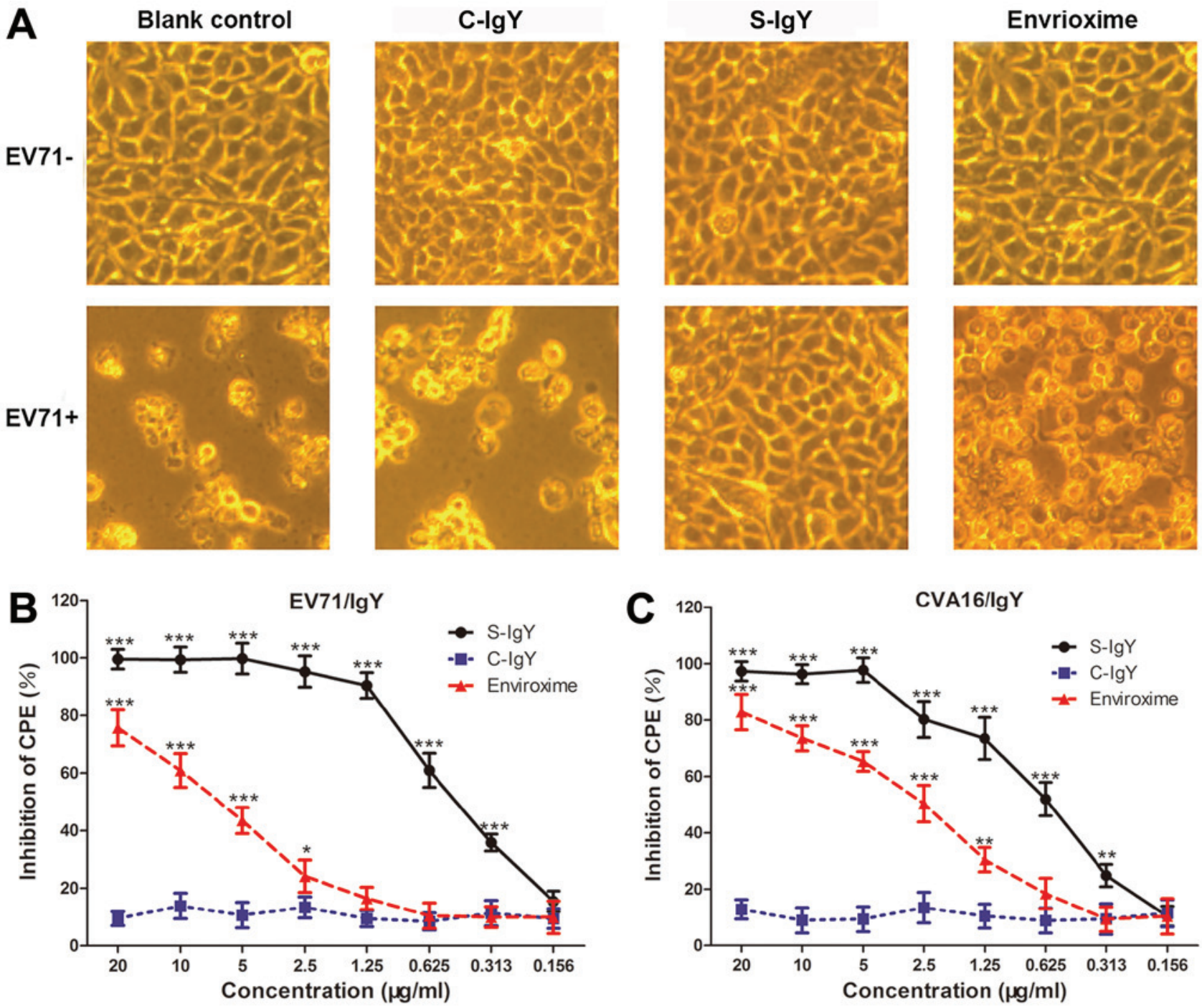

Figure 4. In vitro neutralization assays in RD cells. (A) RD cells were infected with or without EV71, and the cells were treated with PBS (blank control), negative control IgY (C-IgY), S-IgY or Envrioxime. A representative image from each treatment group is indicated (magnification, $\mathrm{x} 400$ ). (B and C) Dose-response inhibitory effect of IgY on CPE in RD cells. (B) EV71-infected RD cells and (C) CVA16-infected RD cells were treated with different concentrations of the $\mathrm{C}$-IgY, the isolated S-IgY or Envrioxime as described in (A). The ability of the antibodies to inhibit CPE was determined using the neutralization assay. CPE values were expressed relative to those for cells with no antibody treatment (control CPE value, $0 \%$ ). Data were presented as the mean \pm standard deviation of three independent experiments. ${ }^{*} \mathrm{P}<0.05,{ }^{* *} \mathrm{P}<0.01$ and ${ }^{* * * *} \mathrm{P}<0.001$ vs. C-IgY. RD, rhabdomyosarcoma; IgY, immunoglobulin Y; EV71, enterovirus 71; CVA16, coxsackievirus A16; C-IgY, negative control IgY; S-IgY, specific IgY; CPE, cytopathic effect.

twice by $45 \%$ saturation of $\left(\mathrm{NH}_{4}\right)_{2} \mathrm{SO}_{4}$ and $13 \%$ mass fraction of $\mathrm{Na}_{2} \mathrm{SO}_{4}$. This markedly improved the purity of $\mathrm{IgY}$, however, the SDS-PAGE results indicated that some impurity bands were still present in the samples, which may include some low density lipoproteins and active proteins. The purity of the IgY was determined to be over $85 \%$ according to gel system software Bandscan 5.0.

IgY cross binds to the structural proteins VPO, VPI and VP3 of EV71 and CVA16. The titer of the purified IgY was measured with a bidirectional immune agar diffusion test. As indicated in Fig. 3A and B, a white precipitation line was identified between the antigen hole in the center and the antibody wells with dilution ratios of 1:2,1:4, and 1:8, but no precipitation line was indicated between the PBS wells and the antigen wells. These data suggested that the purified S-IgY has the ability to specifically cross bind to the antigens of EV71 and CVA16.
The results of western blotting further confirmed that the S-IgY exhibited a good immunological binding reaction with the viral proteins of EV71 and CVA16, whereas neither EV71 nor CVA16 had immunoreactivity with C-IgY (Fig. 3C and D), suggesting that the purified $\operatorname{IgY}$ specifically recognizes the proteins of EV71 and CVA16 strains.

The proteins of EV71 and CVA16 viruses in the samples were identified to be $36 \mathrm{kDa}$ for VP1 and $28 \mathrm{kDa}$ for VP3. The predicted molecular weights of the VP1 protein is $35 \mathrm{kDa}$ and $26 \mathrm{kDa}$ for VP3 $(41,42)$. VP1 protein of EV71 and CVA16 was verified with VP1 monoclonal antibody (Fig. 3C and D, lanes 3 and 4), and the purified IgY was verified with a commercial VP1 protein (Fig. 3E). Taken together, these data indicate that the IgY isolated from the egg yolks of EV71-immunized BWEL-SPF chickens specifically cross binds to EV71 and CVA16 viruses, and these data are consistent with the results of ELISA. 

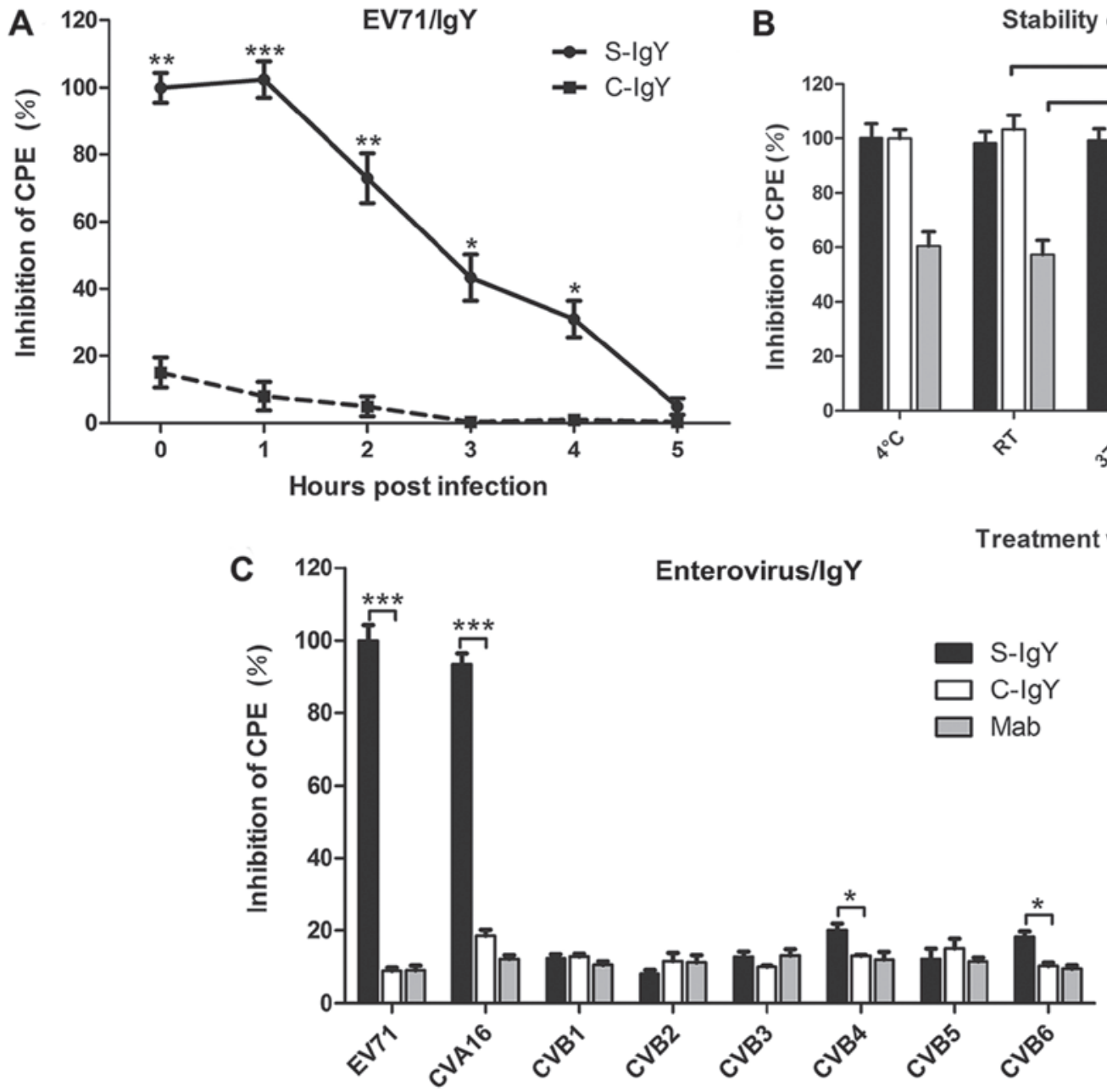

Enterovirus

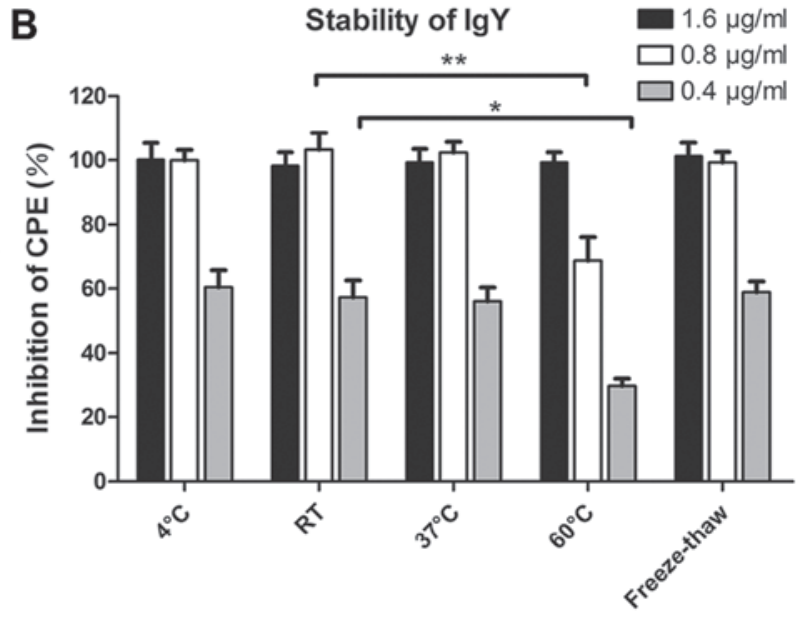

Treatment with $\lg Y$

Figure 5. Characterization of the IgY bioactivity by in vitro neutralization assay. (A) Time-dependent inhibitory effect of the S-IgY on EV71-induced CPE in RD cells. RD cells were infected with EV71 and treated with C-IgY or S-IgY at different time points following EV71 infection. CPE values were expressed relative to those for cells with no antibody treatment (control CPE value, $0 \%$ ). ${ }^{*} \mathrm{P}<0.05,{ }^{* *} \mathrm{P}<0.01$ and ${ }^{* * *} \mathrm{P}<0.001$ vs. C-IgY (Student's t-test). (B) Effect of physical factors (temperature and freeze-thaw) on the S-IgY bioactivity in RD cells. RD cells were infected with EV71 and treated with IgY $(0.4,0.8$, or $1.6 \mu \mathrm{g} / \mathrm{ml})$ following exposure of the IgY to different temperatures for $48 \mathrm{~h}$, or by freezing-thawing for five times. CPE values were expressed relative to those for cells with no antibody treatment (control CPE value, $0 \%$ ). ${ }^{*} \mathrm{P}<0.05$ and ${ }^{* *} \mathrm{P}<0.01{ }^{*}$ vs. RT IgY. (C) Inhibitory effect of the S-IgY on CPE induced by different enterovirus strains. RD cells were infected with eight different enterovirus strains, and the cells were treated with the C-IgY, the S-IgY or Mab. CPE values were expressed relative to those for cells with no antibody treatment (control CPE value, $0 \%$ ). Data were presented as the mean \pm standard deviation of three independent experiments. ${ }^{*} \mathrm{P}<0.05$ and ${ }^{* * *} \mathrm{P}<0.001$ as indicated. Mab, IgY monoclonal antibody; RD, rhabdomyosarcoma; IgY, immunoglobulin Y; EV71, enterovirus 71; C-IgY, negative control IgY; S-IgY, specific IgY; CPE, cytopathic effect.

IgY cross blocks the CPE induced by EV71 and CVA16 in vitro. The protective effect of the purified IgY on enterovirusinduced CPE in RD cells was assessed by neutralization assay in vitro. As indicated in Fig. 4A, RD cells in the EV71 non-infected groups were normal and healthy, indicating that the IgY and the positive control drug Envrioxime themselves had no cytotoxic effect in RD cells. Once the cells were infected with EV71 strains, different degrees of CPE (atrophied, rounded, shedding and apoptosis) appeared in the blank control group, the C-IgY group and the Envrioxime group, whereas RD cells did not exhibit CPE in the S-IgY group, suggesting a protecting effect of the specific IgY on EV71 infection in RD cells (Fig. 4A). Fig. 4B indicated that the IgY had a strong anti-EV71 activity in vitro at the concentrations of $1.25,2.5,5,10$, and $20 \mu \mathrm{g} / \mathrm{ml}$. The results in Fig. $4 \mathrm{C}$ revealed that $\mathrm{IgY}$ had a strong anti-CVA16 activity in vitro at the concentrations of $2.5,5,10$, and $20 \mu \mathrm{g} / \mathrm{ml}$, which substantially inhibited EV71- or CVA16-induced CPE and blocked infectivity of the virus; however, lower concentrations of the IgY did not prevent from the virus infection of RD cells.

To understand the time-dependent protection of the S-IgY against enterovirus infection, RD cells were infected with EV71 and then IgY was added to the cells at different time points after infection. The present data indicated that the IgY inhibited $>70 \%$ of EV71-induced CPE in RD cells when the IgY was added $2 \mathrm{~h}$ post-infection, and inhibited $>40 \%$ of EV71-induced CPE when the IgY was added $3 \mathrm{~h}$ post-infection (Fig. 5A).

The stability of antiviral activity was determined for the isolated IgY. As observed in Fig. 5B, purified IgY was stable after $48 \mathrm{~h}$ at room temperature at $4^{\circ} \mathrm{C}$ and $37^{\circ} \mathrm{C}$, and the inhibition rate was almost $100 \%$ when the cells were treated with 1.6 and $0.8 \mu \mathrm{g} / \mathrm{ml} \mathrm{IgY} \mathrm{after} 48 \mathrm{~h}$ at $60^{\circ} \mathrm{C}$. Furthermore, there was no decrease in antiviral activity observed with S-IgY 
after freeze thawing five times (Fig. 5B), indicating that the freeze-thaw cycle did not impair IgY activity.

The antiviral activity of the purified IgY in 8 different strains of enterovirus demonstrated that the S-IgY had a strong inhibitory activity against EV71 and CVA16 strains $(\mathrm{P}<0.001)$, but had only marginal or no antiviral activity in the 6 other strains of the enterovirus examined, including CVB1, CVB2, CVB3, CVB4, CVB5, and CVB6 (Fig. 5C). The results revealed that the S-IgY has a differential antiviral activity among different types of enterovirus, further suggesting that the IgY isolated from EV71-immunized chicken egg yolks has a specific protection against EV71- and CVA16-induced infections.

\section{Discussion}

EV71 and CVA16 belong to the small RNA family and enterovirus genus and have approximately the same structure (43). Of the four structural proteins of EV71 and CVA16, VP4 is located inside the capsid and connects with RNA (44); VP1, VP2 and VP3 are located on the surface of the capsid; and VP2 and VP4 are cleaved from the VP0 protein by autocatalytic action that involves virion stability and infectivity $(45,46)$. Previous findings suggest that the antigenic determinant is based on the surface proteins, VP1 and VP3 (47). In the treatment of HFMD, inactivated EV71 virus vaccine has been proved to have immunogenicity, but it has no cross protection against other entericviruses, such as CVA16, in phase III clinical trials (48). Lim et al (49) screened monoclonal antibodies that can recognize the N-terminal of VP1 by passive immunization. Their study demonstrated the cross-neutralization of monoclonal antibodies against multiple EV71 subtype strains; however, there was no effect on the CVA16 strains.

In the present study, the results of the neutralization assay revealed that S-IgY cross blocked CPE induced by EV71 and CVA16 in a dose-dependent manner in vitro. Furthermore, bidirectional immune agar diffusion testing and western blotting further demonstrated that the isolated IgY cross bound to the envelope proteins VP1 and VP3 of EV71 and CVA16, suggesting that the inhibitory effect of IgY on EV71and CVA16-induced CPE is mediated through targeting VP1 and VP3 structural proteins. Therefore, it was concluded that the isolated $\mathrm{IgY}$ is likely to be effective in recognizing the sequential epitopes or conformational structure of VP1 and VP3, preventing EV71 and CVA16 from entering and infecting host cells, and ultimately preventing and treating EV71- and CVA16-caused infections. Notably, chicken antibodies may recognize the sequential epitopes or conformational structure.

IgY is the sum of antibodies extracted from the egg yolk of immunized BWEL-SPF chickens, of which 2-10\% have antigen specificity (50). In the present study, $150 \mathrm{mg} \operatorname{IgY}$ was extracted from each egg. Notably, the total IgY produced by an immunized chicken in a year is 20 times as much as the IgG produced by a immunized rabbit (51). The protein in egg yolk is predominantly divided into WSFs and water-insoluble fractions. In the present study, the results indicated that the levels of the IgY in the egg yolk were significantly increased following immunization, which may be due to the increase in the age of the chickens (33). The SDS-PAGE results revealed that the purified IgY was composed of a 70-kDa H chain and a $30-\mathrm{kDa} \mathrm{L}$ chain, which is consistent with the literature (52), suggesting that IgY antibody with high purity can be obtained by the water dilution combined with sulfate precipitation. The indirect ELISA for measuring the S-IgY titer and the growth-decline rule indicated that the titer of antibody peaked at week 7 after the initial immunization and was maintained at a higher level for $\sim 4$ weeks compared with C-IgY, the antibody levels decreased gradually after week 11 . The high titer, suitable purity and long duration of the $\mathrm{IgY}$ in the immunized egg yolks make it possible for manufacturing plants to prepare a large quantity of $\mathrm{IgY}$.

In conclusion, the present findings indicated that the levels of S-IgY were significantly increased in chicken egg yolk following immunization with EV71. It was also revealed that IgY cross blocked CPE induced by EV71 and CVA16, and that the IgY cross bound to the envelope proteins VP1 and VP3 of EV71 and CVA16, suggesting that the cross protection of IgY against EV71 and CVA16 infection may be mediated through targeting VP1 and VP3 structural proteins of the two viruses. These findings provide a scientific basis for developing IgY as a cross passive immunotherapy for EV71- or CVA16-induced HFMD. Further in vivo studies in preclinical animal models with this cross immunotherapy are warranted.

\section{Acknowledgements}

The authors would like to thank Professor Qingdi Quentin Li (National Institute of Allergy and Infectious Diseases, National Institutes of Health, Bethesda, USA) for carefully editing this manuscript.

\section{Funding}

The present study was supported by grants from the National Science Foundation of China (grant no. 81560574) and the Bagui Scholar Foundation of He Songqing (grant no. 2016GXNSFFA380003).

\section{Availability of data and materials}

All datasets used and/or analyzed during the current study are available from the corresponding author on reasonable request.

\section{Authors' contributions}

JW, YY, SW and QX contributed to the conception and design of the study. EG, YZ, NT JW, YY and QX performed the experiments. JW, YY, SW, QX and EG prepared the manuscript. SW and SH performed the statistical analysis. All authors read and approved the final manuscript.

\section{Ethics approval and consent to participate}

The procedure strictly followed the Guide for the EU Directive for animal experiments, the protocols use in the current study were approved by the Institutional Animal Care and Use Committee of Guilin Medical University (Guilin, China).

\section{Patient consent for publication}

Not applicable. 


\section{Competing interests}

The authors declare that they have no competing interests.

\section{References}

1. Solomon T, Lewthwaite P, Perera D, Cardosa MJ, McMinn P and Ooi MH: Virology, epidemiology, pathogenesis, and control of enterovirus 71. Lancet Infect Dis 10: 778-790, 2010.

2. Yip CC, Lau SK, Woo PC and Yuen KY: Human enterovirus 71 epidemics: What's next? Emerg Health Threats J 6: 19780, 2013

3. Liu SL, Pan H, Liu P, Amer S, Chan TC, Zhan J, Huo X, Liu Y, Teng Z, Wang L and Zhuang H: Comparative epidemiology and virology of fatal and nonfatal cases of hand, foot and mouth disease in mainland China from 2008 to 2014. Rev Med Virol 25: $115-128,2015$

4. Anastasina M, Domanska A, Palm K and Butcher S: Human picornaviruses associated with neurological diseases and their neutralization by antibodies. J Gen Virol 98: 1145-1158, 2017

5. Zhu FC, Meng FY, Li JX, Li XL, Mao QY, Tao H, Zhang YT, Yao X, Chu K, Chen QH, et al: Efficacy, safety, and immunology of an inactivated alum-adjuvant enterovirus 71 vaccine in children in China: A multicentre, randomised, double-blind, placebo-controlled, phase 3 trial. Lancet 381: 2024-2032, 2013.

6. Wright HT Jr, Landing BH, Lennette EH and McAllister RM Fatal infection in an infant associated with Coxsackie virus group A, type 16. N Engl J Med 268: 1041-1044, 1963.

7. Legay F, Leveque N, Gacouin A, Tattevin P, Bouet J, Thomas R and Chomelt JJ: Fatal coxsackievirus A-16 pneumonitis in adult Emerg Infect Dis 13: 1084-1086, 2007.

8. Goto K, Sanefuji M, Kusuhara K, Nishimura Y, Shimizu H, Kira R, Torisu H and Hara T: Rhombencephalitis and coxsackievirus A16. Emerg Infect Dis 15: 1689-1691, 2009.

9. Wang CY, Li Lu F, Wu MH, Lee CY and Huang LM: Fatal coxsackievirus A16 infection. Pediatr Infect Dis J 23: 275-276, 2004

10. Chen WJ, Arnold JC, Fairchok MP, Danaher PJ, McDonough EA, Blair PJ, Garcia J, Halsey ES, Schofield C, Ottolini M, et al Epidemiologic, clinical, and virologic characteristics of human rhinovirus infection among otherwise healthy children and adults: Rhinovirus among adults and children. J Clin Virol 64 74-82, 2015.

11. Li R, Liu L, Mo Z, Wang X, Xia J, Liang Z, Zhang Y, Li Y, Mao Q, Wang J, et al: An inactivated enterovirus 71 vaccine in healthy children. N Engl J Med 370: 829-837, 2014

12. Tung WS, Bakar SA, Sekawi Z and Rosli R: DNA vaccine constructs against enterovirus 71 elicit immune response in mice. Genet Vaccines Ther 5: 6, 2007.

13. Foo DG, Alonso S, Chow VT and Poh CL: Passive protection against lethal enterovirus 71 infection in newborn mice by neutralizing antibodies elicited by a synthetic peptide. Microbes Infect 9: 1299-1306, 2007.

14. Kirk K, Poh CL, Fecondo J, Pourianfar H, Shaw J and Grollo L: Cross-reactive neutralizing antibody epitopes against Enterovirus 71 identified by an in silico approach. Vaccine 30: 7105-7110, 2012

15. Foo DG, Alonso S, Phoon MC, Ramachandran NP, Chow VT and Poh CL: Identification of neutralizing linear epitopes from the VP1 capsid protein of Enterovirus 71 using synthetic peptides. Virus Res 125: 61-68, 2007

16. Zhou H, Wang G, Li XF, Li Y, Zhu SY, Qin CF and Tang R: Alumina-encapsulated vaccine formulation with improved thermostability and immunogenicity. Chem Commun (Camb) 52 6447-6450, 2016.

17. Cao R, Han J, Deng Y, Yu M, Qin E and Qin C: Presence of high-titer neutralizing antibodies against enterovirus 71 in intravenous immunoglobulin manufactured from Chinese donors. Clin Infect Dis 50: 125-126, 2010

18. Zhang G, Zhou F, Gu B, Ding C, Feng D, Xie F, Wang J, Zhang C, Cao Q, Deng Y, et al: In vitro and in vivo evaluation of ribavirin and pleconaril antiviral activity against enterovirus 71 infection. Arch Virol 157: 669-679, 2012.

19. Chong P, Hsieh SY, Liu CC, Chou AH, Chang JY, Wu SC, Liu SJ, Chow YH, Su IJ and Klein M: Production of EV71 vaccine candidates. Hum Vaccin Immunother 8: 1775-1783, 2012.

20. Reed Z and Cardosa MJ: Status of research and development of vaccines for enterovirus 71. Vaccine 34: 2967-2970, 2016.
21. Li Y, Bao H, Zhang X, Zhai M, Bao X, Wang D and Zhang S: Epidemiological and genetic analysis concerning the non-enterovirus 71 and non-coxsackievirus A16 causative agents related to hand, foot and mouth disease in Anyang city, Henan Province, China, from 2011 to 2015. J Med Virol 89: 1749-1758, 2017.

22. Mizuta K, Aoki Y, Suto A, Ootani K, Katsushima N, Itagaki T, Ohmi A, Okamoto M, Nishimura H, Matsuzaki Y, et al: Cross-antigenicity among EV71 strains from different genogroups isolated in Yamagata, Japan, between 1990 and 2007. Vaccine 27: 3153-3158, 2009.

23. Zhang Y, Zhu Z, Yang W, Ren J, Tan X, Wang Y, Mao N, Xu S, Zhu S, Cui A, et al: An emerging recombinant human enterovirus 71 responsible for the 2008 outbreak of hand foot and mouth disease in Fuyang city of China. Virol J 7: 94, 2010.

24. Jolles S, Sewell WA and Misbah SA: Clinical uses of intravenous immunoglobulin. Clin Exp Immunol 142: 1-11, 2005.

25. Ameratunga R, Sinclair J and Kolbe J: Increased risk of adverse events when changing intravenous immunoglobulin preparations. Clin Exp Immunol 136: 111-113, 2004.

26. Han JF, Cao RY, Deng YQ, Tian X, Jiang T, Qin ED and Qin CF: Antibody dependent enhancement infection of enterovirus 71 in vitro and in vivo. Virol J 8: 106, 2011

27. Wang W, Wang EQ and Balthasar JP: Monoclonal antibody pharmacokinetics and pharmacodynamics. Clin Pharmacol Ther 84: 548-558, 2008

28. Sgro C: Side-effects of a monoclonal antibody, muromonab CD3/orthoclone OKT3: Bibliographic review. Toxicology 105: $23-29,1995$.

29. Tini M, Jewell UR, Camenisch G, Chilov D and Gassmann M: Generation and application of chicken egg-yolk antibodies. Comp Biochem Physiol A Mol Integr Physiol 131: 569-574, 2002.

30. Lee J, Kang HE and Woo HJ: Stability of orally administered immunoglobulin in the gastrointestinal tract. J Immunol Methods 384: 143-147, 2012.

31. Nilsson E, Stålberg J and Larsson A: IgY stability in eggs stored at room temperature or at $+4^{\circ} \mathrm{C}$. Br Poult Sci 53: 42-46, 2012

32. Schade R, Staak C, Erhard M, Hugl H, Koch G and Hendriksen C: The production of avian (Egg Yolk) Antibodies: IgY. ATLA 24 925-934, 1997

33. Ulmer-Franco AM, Cherian G, Quezada N, Fasenko GM and McMullen LM: Hatching egg and newly hatched chick yolk sac total IgY content at 3 broiler breeder flock ages. Poult Sci 91: 758-764, 2012.

34. Zhang WW: The use of gene-specific IgY antibodies for drug target discovery. Drug Discov Today 8: 364-371, 2003.

35. Yang YH, Park D, Yang G, Lee SH, Bae DK, Kyung J, Kim D, Choi EK, Son JC, Hwang SY and Kim YB Anti-Helicobacter pylori effects of IgY from egg york of immunized hens. Lab Anim Res 28: 55-60, 2012

36. Akbari MR, Ahmadi A, Mirkalantari S and Salimian J: Anti-Vibriocholerae IgY antibody inhibits mortality in suckling mice model. J Natl Med Assoc 110: 84-87, 2018.

37. Thu HM, Myat TW, Win MM, Thant KZ, Rahman S, Umeda K, Nguyen SV, Icatlo FC Jr, Higo-Moriguchi K, Taniguchi K, et al: Chicken Egg Yolk antibodies (IgY) for prophylaxis and treatment of rotavirus diarrhea in human and animal neonates: A concise review. Korean J Food Sci Anim Resour 37: 1-9, 2017.

38. Fu CY, Huang H, Wang XM, Liu YG, Wang ZG, Cui SJ, Gao HL, Li Z, Li JP and Kong XG: Preparation and evaluation of anti-SARS coronavirus IgY from yolks of immunized SPF chickens. J Virol Methods 133: 112-115, 2006.

39. Xiao Y, Gao X, Maragh S, Telford WG and Tona A: Cell lines as candidate reference materials for quality control of ERBB2 amplification and expression assays in breast cancer. Clin Chem 55: 1307-1315, 2009

40. Lee MS, Cohen B, Hand J and Nokes DJ: A simplified and standardized neutralization enzyme immunoassay for the quantification of measles neutralizing antibody. J Virol Method 78: 209-217, 1999.

41. Feng Q, He Y and Lu J: Virus-like particles produced in pichia pastoris induce protective immune responses against coxsackievirus A16 in mice. Med Sci Monit 22: 3370-3382, 2016.

42. Liu CC, Chou AH, Lien SP, Lin HY, Liu SJ, Chang JY, Guo MS, Chow YH, Yang WS, Chang KH, et al: Identification and characterization of a cross-neutralization epitope of Enterovirus 71. Vaccine 29: 4362-4372, 2011.

43. Ang LW, Koh BK, Chan KP, Chua LT, James L and Goh KT: Epidemiology and control of hand, foot and mouth disease in Singapore, 2001-2007. Ann Acad Med Singapore 38: 106-112, 2009. 
44. Wang X, Peng W, Ren J, Hu Z, Xu J, Lou Z, Li X, Yin W, Shen X, Porta $\mathrm{C}$, et al: A sensor-adaptor mechanism for enterovirus uncoating from structures of EV71. Nat Struct Mol Biol 19: 424-429, 2012.

45. Zhang YX, Huang YM, Li QJ, Li XY, Zhou YD, Guo F, Zhou JM and Cen S: A highly conserved amino acid in VP1 regulates maturation of enterovirus 71. PLoS Pathog 13: e1006625, 2017.

46. Curry S, Fry E, Blakemore W, Abu-Ghazaleh R, Jackson T, King A, Lea S, Newman J and Stuart D: Dissecting the roles of VPO cleavage and RNA packaging in picornavirus capsid stabilization: The structure of empty capsids of foot-and-mouth disease virus. J Virol 71: 9743-9752, 1997.

47. Kristensen T, Newman J, Guan SH, Tuthill TJ and Belsham GJ: Cleavages at the three junctions within the foot-and-mouth disease virus capsid precursor $(\mathrm{P} 1-2 \mathrm{~A})$ by the $3 \mathrm{C}$ protease are mutually independent. Virology 522: 260-270, 2018.

48. Chong P, Liu CC, Chow YH, Chou AH and Klein M: Review of enterovirus 71 vaccines. Clin Infect Dis 60: 797-803, 2015.
49. Lim XF, Jia Q, Khong WX, Yan B, Premanand B, Alonso S, Chow VT and Kwang J: Characterization of an isotype-dependent monoclonal antibody against linear neutralizing epitope effective for prophylaxis of enterovirus 71 infection. PLoS One 7: e29751, 2012.

50. Mine Y and Kovacs-Nolan J: Chicken egg yolk antibodies as therapeutics in enteric infectious disease: A review. J Med Food 5: 159-169, 2002.

51. Solhi R, Alebouyeh M, Khafri A, Rezaeifard M and Aminian M: In vitro evaluation of cross-strain inhibitory effects of IgY polyclonal antibody against $H$. pylori. Microb Pathog 110: 682-687, 2017.

52. Müller S, Schubert A, Zajac J, Dyck T and Oelkrug C: IgY antibodies in human nutrition for disease prevention. Nutr J 14: 109, 2015. 